\title{
The relationship between physician and cancer patient when initiating adjuvant treatment and its association with sociodemographic and clinical variables
}

\author{
P. Jimenez-Fonseca ${ }^{1}$ (D) C. Calderon ${ }^{2} \cdot$ A. Carmona-Bayonas ${ }^{3} \cdot$ M. M. Muñoz ${ }^{4} \cdot$ R. Hernández $^{5} \cdot$ M. Mut Lloret $^{6}$. \\ I. Ghanem ${ }^{7}$. C. Beato ${ }^{8} \cdot$ D. Cacho Lavín ${ }^{9} \cdot$ A. Ivars Rubio ${ }^{3} \cdot$ R. Carrión ${ }^{10} \cdot$ C. Jara ${ }^{11}$
}

Received: 17 March 2018 / Accepted: 26 March 2018

๑) Federación de Sociedades Españolas de Oncología (FESEO) 2018

\begin{abstract}
Purpose The aim of this study was to analyze differences in physician and patient satisfaction in shared decision-making $(\mathrm{SDM})$; patients' emotional distress, and coping in subjects with resected, non-metastatic cancer.

Methods 602 patients from 14 hospitals in Spain were surveyed. Information was collected regarding physician and patient satisfaction with SDM, participants' emotional distress and coping, as well as patient sociodemographic and clinical characteristics by means of specific, validated questionnaires.

Results Overall, $11 \%$ of physicians and $19 \%$ of patients were dissatisfied with SDM; $22 \%$ of patients presented hopelessness or anxious preoccupation as coping strategies, and $56 \%$ presented emotional distress. By gender, female patients showed a higher prevalence of dissatisfaction with SDM (23 vs 14\%), anxious preoccupation ( 26 vs 17\%), and emotional distress (63 vs $44 \%$ ) than males. Hopelessness was more prevalent in individuals with stage III disease than those with stages I-II (28 vs $18 \%)$.

Conclusion Physicians must be mindful of the importance of emotional support and individual characteristics when communicating treatment options, benefits, and adverse effects of each alternative to oncological patients.
\end{abstract}

Keywords Cancer $\cdot$ Coping $\cdot$ Distress $\cdot$ Medical oncologist $\cdot$ Satisfaction $\cdot$ Shared decision-making

\section{Introduction}

In recent years, $30-40 \%$ of cancer patients have been seen to present emotional distress and maladaptive coping strategies [1]. The confirmation of diagnosis of cancer has a huge

P. Jimenez-Fonseca

palucaji@hotmail.com

1 Department of Medical Oncology, Hospital Universitario Central de Asturias, Planta-1, Bloque D, Avenida Roma sn, 33011 Oviedo, Spain

2 Department of Clinical Psychology and Psychobiology, Faculty of Psychology, University of Barcelona, Barcelona, Spain

3 Department of Hematology and Medical Oncology, Hospital Universitario Morales Meseguer, Murcia, Spain

4 Department of Medical Oncology, Hospital Virgen de La Luz, Cuenca, Spain

5 Department of Medical Oncology, Hospital Universitario de Canarias, Tenerife, Spain emotional impact that generates fear, anxiety, uncertainty, sadness, and anger. The treatments generally applied to cancer, such as surgery, chemotherapy, and radiotherapy, tend to entail multiple side effects and decline in the patient's physical and emotional status [1]. Given that psychological

6 Department of Medical Oncology, Hospital Universitario Son Espases, Mallorca, Spain

7 Department of Medical Oncology, Hospital Universitario La Paz, Madrid, Spain

8 Department of Medical Oncology, Hospital Universitario Virgen de La Macarena, Sevilla, Spain

9 Department of Medical Oncology, Hospital Universitario Marqués de Valdecilla, Santander, Spain

10 Department of Medical Oncology, Hospital Universitario del Sureste, Arganda del Rey, Madrid, Spain

11 Department of Medical Oncology, Hospital Universitario Fundación Alcorcón, Universidad Rey Juan Carlos, Madrid, Spain 
distress and psychosocial problems appear to negatively affect oncological patient's quality of life, screening and assessing these issues should be a routine in clinical practice [2, 3]. However, little attention is paid in our setting, with few large, multicenter studies conducted in Spain. For instance, the Southern European Psycho-Oncological Study (SEPOS) revealed that Spanish and Italian individuals with cancer displayed higher levels of anxiety and depression and lower levels of resignation compared to their Portuguese counterparts, in addition to lower levels of spirituality [2, 4].

Another factor is the repercussions of distress and psychosocial problems on the physician-patient relationship, potentially affecting communication between them $[2,5]$. The individual's interaction with their oncologist influences how they experience their illness on many levels. Some studies point to a correlation between a lack of ability on the physician's part to listen and respond to patients' emotional concerns and needs and patients' dissatisfaction [6] and worse quality of life [7]. In line with these findings, oncologists' attention and emotional support and their attitude toward the patient enhance satisfaction [7, 8], coping, and emotional well-being $[9,10]$. Patient characteristics, such as gender, age, tumor type, or stage of disease, as well as their coping styles and emotional status also influence this well-being. Likewise, all of these factors influence the doctor-patient relationship.

With this background and with the aim of expanding our understanding in this area, the objective of this study was to analyze differences in physician and patient satisfaction with shared decision-making (SDM), as well as patients' emotional distress and coping based on gender and age, and on the basis of the location of the tumor and the stage of disease in a sample of Spanish patients with resected, non-metastatic cancer who were going to receive adjuvant chemotherapy.

\section{Methods}

The study was conducted at the department of Medical Oncology at 14 hospitals in Spain. Patients completed selfreport questionnaires prior to initiating chemotherapy. The study was approved by the Ethics Review Board at each institution and by the Spanish Agency of Medicines and Medical Devices (AEMPS). Specifically trained medical oncologists collected and updated data, via a web-based platform (http://www.neocoping.es). Of the 687 patients screened, 85 were not eligible (17 did not meet inclusion criteria; 23 met exclusion criteria; and 45 had incomplete data).

Physicians' satisfaction was measured with the SDM Questionnaire-Physician's version (SDM-Q-Doc), a questionnaire that evaluates the physician's perspective on SDM and how well they follow it with their patients [11]. It was adapted to Spanish by Calderon et al. [12] and subsequently validated. It consists of nine items, each of which describes one step of the process. The items are scored from 0 to 5 on a six-point Likert scale as "completely disagree" (0) to "completely agree" (5). A simple sum score ranging from 0 to 45 is obtained and shows good internal consistency in Spain $(\alpha=0.90)$ [12].

Patients' satisfaction was measured with the SDM Questionnaire-Patient's version (SDM-Q-9), a brief, valid, reliable questionnaire that evaluates the SDM process from the patient's perspective [13], adapted to Spanish by De las Cuevas et al. [14]. It contains nine items, each describing one step of the SDM process [15] and was developed to assess the degree to which patients feel involved in the decisionmaking process. Items are scored from 0 to 5 on a six-point Likert scale (5). Standard scoring is a simple summary score with possible values between 0 and 45 ; the scale has proven good internal consistency in Spain $(\alpha=0.88)$ [14]. Both scales (SDM-Q-Doc and SDM-Q-9) were dichotomized at the mean plus one standard deviation to differentiate satisfied from dissatisfied cases. This criterion results in biased distributions but should be considered as "the standard" in this context.

The Mini-Mental Adjustment to Cancer (Mini-MAC) scale [16] was used to assess patients' cognitive and behavioral attitude toward cancer, specifically hopelessness and anxious preoccupation [17]. Both subscales consist of eight items, the first measuring the tendency to adopt a pessimistic, despairing attitude regarding the illness and the second one that rates the tendency to feel worried and preoccupied about the disease. Each item is rated on a 4-point Likert scale. Scores for both hopelessness and anxious preoccupation varied from 0 to 24 and cutoff scores for these items (mean score $\pm 1 \mathrm{SD}$ ) were used to identify cases of maladaptive coping, as per the MAC user's manual [16].

Emotional distress was appraised by the Brief Symptom Inventory (BSI), one of the most widely used instruments to rate emotional distress in clinical patients [18] consisting of 18 items. Each item is scored on a 5-point Likert scale. Scores for each subscale range from 0 to 24 . Raw-scores are converted to $T$-scores based on gender-specific normative data from a non-patient population, with higher scores indicating greater anxiety or depression. To identify individuals with significant emotional distress, the BSI-18 applies the clinical case rule [19], originally developed for the SCL-90. According to the BSI-18 Manual, respondents with a $T$-score $\geq 63$ should be classified as having clinically significant distress. The Spanish version of BSI has good reliability and validity in Spanish patients [20]. 


\section{Data analysis}

Distribution and frequency analyses were used to evaluate the sample. The relationships between clinical and demographic factors and the presence of physician and patient satisfaction/dissatisfaction with SDM; patients' maladaptive coping, and emotional distress were tested using Chi-square and $t$ test or ANOVA $(F)$. The $\chi^{2}$ test was used to compare categorical variables between the different patient groups; $t$ test or ANOVA $(F)$ for independent samples was used to compare continuous variables. Univariate models were fitted for all clinical and demographic variables: gender (male/ female), age ( $\leq 44,45-54,55-64,65-74, \geq 75$ years), tumor (colorectal, breast, stomach, and others), and stage (I-II/III). A raw-score $\leq 27$ was used to identify physicians' dissatisfaction, while a raw-score $\leq 20$, indicated patients' dissatisfaction. In patients, a raw-score $\geq 9$ established hopelessness and a raw-score $\geq 16$ identified anxious preoccupation. Analyses were conducted using SPSS 23.0 version and an alpha level of 0.05 .

\section{Results}

A total of 602 patients participated in the study (244 with colorectal, 203 with breast, 38 with stomach, and 117 with other cancers). The mean age was $59 \pm 12$ years. Most participants were female $(n=358,60 \%)$, married or lived with a partner (77\%), and had completed primary education (56\%). The most common employment status was retired (59\%) (see Table 1 for details).

Physicians' general characteristics are reported elsewhere [12]. In summary, patients were recruited by 30 medical oncologists from 14 Spanish hospitals; $78.1 \%(n=25)$ of these specialists were female; mean age was $35 \pm 7.4$ years, with $11.9 \pm 8.8$ years of experience in caring for cancer patients. Most were super-specialists (68.8\%) working at a public, teaching hospital (53.1\%).

\section{Physician-patient satisfaction and psychological variables by gender and age}

In the sample as a whole, $11 \%$ of physicians and $19 \%$ of patients were dissatisfied with SDM; while among patients, $22 \%$ displayed hopelessness or anxious preoccupation as coping strategies, and 56\% exhibited emotional distress.

Table 2 presents the descriptive results for the psychological scales separated by gender and age. Insofar as physician-patient interaction is concerned, physicians' satisfaction with SDM did not differ according to the patients' gender or age. In contrast, patient satisfaction differed by gender, in that males scored higher on satisfaction with $\operatorname{SDM}\left(t_{(600)}=3.980, p<0.001\right)$, whereas among women, dissatisfaction was more prevalent than among men (23 vs $14 \%, \chi^{2}=8.704, p=0.003$; odds ratio $(\mathrm{OR})=1.930,95 \%$ confidence interval (CI) 1.241-3.001).

Regarding coping, females showed a slightly higher prevalence of anxious preoccupation than males (26 vs $17 \% ; \chi^{2}=6.670, p=0.010, \mathrm{OR}=1.712,95 \% \mathrm{CI}$ $1.135-2.583)$, and higher scores on AP $\left(t_{(600)}=-2.507\right.$, $p=0.012$ ), but no differences were detected in hopelessness between males and females. Younger patients

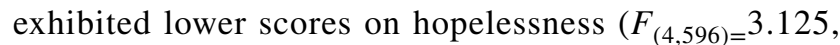
$p=0.015)$ and higher scores on anxious preoccupation $\left(F_{(4,597)}=2.592, p=0.036\right)$; participants aged $\leq 44$ years presented more anxious preoccupation and less hopelessness than those 65 years of age or older.

As regards to the BSI, females displayed a higher prevalence rate of emotional distress than males (63 vs 44\%; $\chi^{2}=19.410, p<0.001, \mathrm{OR}=2.095,95 \%$ CI $\left.1.505-2.918\right)$ and scored higher for emotional distress $\left(t_{(600)}=-5.926\right.$, $p<0.001)$. The prevalence of cases of emotional distress as per the BSI (cut-off $\geq 63$ ) differed across the five age groups $\left(\chi^{2}=24.864, p<0.001\right)$. Subjects 44 years of age or younger suffered more emotional distress than those aged $\geq 65$ years $\left(F_{(4,597)}=8.676, p<0.001\right)$.

Table 1 Patient demographic and clinical characteristics according to the location of the cancer

\begin{tabular}{|c|c|c|c|c|c|}
\hline $\begin{array}{l}\text { Patient demographic and } \\
\text { clinical characteristics }\end{array}$ & $\begin{array}{l}\text { Colorectal }(n=244) \\
N(\%)\end{array}$ & $\begin{array}{l}\text { Breast }(n=203) \\
N(\%)\end{array}$ & $\begin{array}{l}\text { Stomach }(n=38) \\
N(\%)\end{array}$ & $\begin{array}{l}\text { Others }(n=117) \\
N(\%)\end{array}$ & $\begin{array}{l}\text { Total }(n=602) \\
N(\%)\end{array}$ \\
\hline Gender ( $\%$ women $)$ & $90(37)$ & $198(94)$ & $15(39)$ & $55(47)$ & $358(60)$ \\
\hline Age, $M(\mathrm{SD})$ & $63.1(11.1)$ & $52.9(10.8)$ & $65.1(9.9)$ & $59.4(12.8)$ & $59.1(12.2)$ \\
\hline Marital status (\% married) & $195(80)$ & $148(73)$ & $31(82)$ & 87 (74) & $461(77)$ \\
\hline Education (\% primary) & $146(60)$ & $106(52)$ & $24(63)$ & $61(52)$ & $337(56)$ \\
\hline Work (\% retired) & $165(68)$ & $88(43)$ & $28(74)$ & $71(61)$ & $352(59)$ \\
\hline \multicolumn{6}{|l|}{ Stage } \\
\hline $\mathrm{I}-\mathrm{II}$ & $84(35)$ & $181(89)$ & $11(29)$ & $60(61)$ & $336(58)$ \\
\hline III & $159(65)$ & $22(11)$ & $27(71)$ & $38(39)$ & $246(42)$ \\
\hline
\end{tabular}

$M$ mean, $S D$ standard deviation 
Table 2 Perception of physician-patient interaction (SDM), emotional distress (BSI), and coping (Mini-MAC) by gender and age

\begin{tabular}{|c|c|c|c|c|c|c|c|c|c|}
\hline & \multicolumn{3}{|l|}{ Gender } & \multicolumn{6}{|l|}{ Age } \\
\hline & $\begin{array}{l}\text { Male } \\
(n=111)\end{array}$ & $\begin{array}{l}\text { Female } \\
(n=161)\end{array}$ & $\begin{array}{l}p \text { value } \\
\text { (gender) }\end{array}$ & $\begin{array}{l}\leq 44 \\
(n=79)\end{array}$ & $\begin{array}{l}45-54 \\
(n=134)\end{array}$ & $\begin{array}{l}55-64 \\
(n=169)\end{array}$ & $\begin{array}{l}65-74 \\
(n=161)\end{array}$ & $\begin{array}{l}\geq 75 \\
(n=59)\end{array}$ & $p$ value (age) \\
\hline $\begin{array}{l}\text { Physician's } \\
\text { satisfaction } \\
\text { with SDM }\end{array}$ & $32.3(5.2)$ & $32.5(4.9)$ & ns & $33.2(4.8)$ & $32.1(5.3)$ & $32.8(4.8)$ & $32.1(5.1)$ & $31.7(4.9)$ & ns \\
\hline $\begin{array}{l}\text { Patient's } \\
\text { satisfaction } \\
\text { with SDM }\end{array}$ & $30.1(7.2)$ & $27.3(8.8)$ & 0.001 & $28.2(8.4)$ & $27.4(8.5)$ & $28.5(8.1)$ & $28.8(8.3)$ & $28.8(8.3)$ & ns \\
\hline $\begin{array}{l}\text { Hopeless- } \\
\text { ness }\end{array}$ & $4.9(4.4)$ & $4.5(4.5)$ & ns & $3.9(4.1)$ & $4.2(4.3)$ & $4.5(4.3)$ & $5.7(4.7)$ & $4.5(4.5)$ & 0.015 \\
\hline $\begin{array}{l}\text { Anxious } \\
\text { preoccupa- } \\
\text { tion }\end{array}$ & $9.5(5.9)$ & $10.8(6.1)$ & 0.012 & $11.6(5.6)$ & $10.8(6.2)$ & $10.1(5.8)$ & $9.7(6.1)$ & $8.6(6.6)$ & 0.036 \\
\hline $\begin{array}{c}\text { Emotional } \\
\text { distress }\end{array}$ & $61.9(6.1)$ & $65.1(6.8)$ & 0.001 & $66.1(6.6)$ & $65.6(6.7)$ & $63.7(6.6)$ & $62.4(6.5)$ & $61.3(5.7)$ & 0.001 \\
\hline $\begin{array}{l}\text { Physicians' } \\
\text { dissatisfac- } \\
\text { tion } \leq 27\end{array}$ & 11 & 11 & ns & 8 & 15 & 9 & 12 & 12 & ns \\
\hline $\begin{array}{l}\text { Patients' dis- } \\
\text { satisfaction } \\
\leq 20\end{array}$ & 14 & 23 & 0.003 & 18 & 21 & 20 & 18 & 19 & ns \\
\hline $\begin{array}{l}\text { Caseness for } \\
\text { hopeless- } \\
\text { ness }(\geq 9)\end{array}$ & 25 & 20 & ns & 18 & 16 & 19 & 31 & 24 & 0.017 \\
\hline $\begin{array}{l}\text { Caseness for } \\
\text { anxious } \\
\text { preoccupa- } \\
\text { tion }(\geq 16)\end{array}$ & 17 & 26 & 0.010 & 27 & 26 & 20 & 21 & 15 & $\mathrm{~ns}$ \\
\hline $\begin{array}{l}\text { Caseness for } \\
\text { emotional } \\
\text { distress } \\
(\geq 63)\end{array}$ & 44 & 63 & 0.001 & 68 & 66 & 57 & 44 & 41 & 0.001 \\
\hline
\end{tabular}

SDM shared decision-making

\section{Physician-patient satisfaction and psychological variables by tumor and stage}

Table 3 shows the descriptive results for the psychological scales separated by tumor and stage. As far as physicians' $\left(F_{(3,598)}=4.138, p=0.006\right)$ and patients' satisfaction $\left(F_{(3,615)}=3.825, p=0.010\right)$ with the SDM, significant differences were revealed when examined by tumor. Physicians were more satisfied with SDM, as were colon cancer patients, whereas individuals with stomach and breast cancer were the least satisfied. There were no differences in patient satisfaction with the SDM based on tumor stage, although doctors displayed greater satisfaction with stage I-II cancer patients $\left(t_{(580)}=3.723, p<0.001\right)$.

Insofar as coping and emotional distress are concerned, patients with stomach cancer scored highest on hopelessness $\left(F_{(3,598)}=4.854, p=0.002\right)$ and emotional distress $\left(F_{(3,598)}=7.113, p<0.001\right)$. Not only did patients with stage III cancer display a higher prevalence of hopelessness compared with patients with tumor staged I-II (28 vs 18\%; $\chi^{2}=7.323, p=0.07, \mathrm{OR}=1.722,95 \%$ CI 1.159-2.558), were also seen to display more intense hopelessness $\left(t_{(580)}=-2.771, p=0.006\right)$, and anxious preoccupation $\left(t_{(580)}=-2.285, p=0.023\right)$ scores were higher in the group of participants with stage III tumors, albeit no differences were found in emotional distress. See Fig. 1.

\section{Discussion}

This study examines physician and patient dissatisfaction with SDM, and patients' emotional distress and maladaptive coping styles, taking into account patient demographic and clinical variables.

With respect to the primary objective of this study, dissatisfaction with SDM was only present in one out of every ten physicians and one in five patients. These data are congruent with those of other studies that show that oncological 
Table 3 Perception of physician-patient interaction (SDM), emotional distress (BSI), and coping (Mini-MAC) by tumor and stage

\begin{tabular}{|c|c|c|c|c|c|c|c|c|}
\hline & \multicolumn{5}{|l|}{ Tumors } & \multicolumn{3}{|l|}{ Stage } \\
\hline & Colon $(n=244)$ & Breast $(n=203)$ & Stomach $(n=38)$ & Others $(n=117)$ & $p$ value & I-II $(n=336)$ & III $(n=246)$ & $p$ value \\
\hline $\begin{array}{l}\text { Patients' satisfaction } \\
\text { with SDM }\end{array}$ & $33.1(4.3)$ & $32.6(5.1)$ & $31.4(6.8)$ & $31.2(5.5)$ & 0.006 & $33.2(5.1)$ & $31.7(4.4)$ & 0.001 \\
\hline $\begin{array}{l}\text { Physician's satisfaction } \\
\text { with } \mathrm{SDM}^{\mathrm{b}}\end{array}$ & $29.2(7.9)$ & $26.9(9.1)$ & $30.6(6.9)$ & $28.3(8.1)$ & 0.010 & $28.5(8.2)$ & $28.2(8.4)$ & ns \\
\hline Hopelessness & $4.6(4.4)$ & $4.0(4.2)$ & $6.7(4.5)$ & $5.2(4.6)$ & 0.002 & $4.2(4.2)$ & $5.2(4.5)$ & 0.006 \\
\hline Anxious preoccupation & $9.8(6.1)$ & $10.4(6.1)$ & $11.3(5.5)$ & $10.6(6.1)$ & ns & $9.8(6.1)$ & $10.9(6.1)$ & 0.023 \\
\hline Emotional distress & $62.3(6.5)$ & $64.8(6.9)$ & $65.1(6.1)$ & $64.9(6.3)$ & 0.001 & $63.9(6.6)$ & $63.7(6.9)$ & $\mathrm{ns}$ \\
\hline $\begin{array}{l}\text { Physicians' dissatisfac- } \\
\text { tion } \leq 27\end{array}$ & 7 & 13 & 16 & 15 & 0.044 & 10 & 12 & ns \\
\hline $\begin{array}{l}\text { Patients' dissatisfaction } \\
\leq 20\end{array}$ & 16 & 25 & 13 & 19 & $\mathrm{~ns}$ & 19 & 20 & ns \\
\hline $\begin{array}{l}\text { Caseness for hopeless- } \\
\text { ness }(\geq 9)\end{array}$ & 23 & 15 & 37 & 28 & 0.005 & 18 & 28 & 0.007 \\
\hline $\begin{array}{l}\text { Caseness for anxious } \\
\text { preoccupation }(\geq 16)\end{array}$ & 19 & 24 & 21 & 28 & ns & 22 & 23 & ns \\
\hline $\begin{array}{l}\text { Caseness for emotional } \\
\text { distress }(\geq 63)\end{array}$ & 43 & 64 & 68 & 64 & 0.001 & 57 & 52 & ns \\
\hline
\end{tabular}

${ }^{\text {a}}$ Questionnaire-Patient's version (SDM-Q-9)

${ }^{\mathrm{b}}$ Questionnaire-Physician's version (SDM-Q-Doc)

patients in our setting are not terribly interested in participating in making decisions that affect their health and points to this being affected in part, by a paternalistic model that continues to exist in most Spanish hospitals [21, 22]. We also believe that not all oncological patients are prepared or even want to be equally involved or participate in SDM at times of great emotional tension. On the other hand, men and patients with colon cancer are the ones who are most satisfied with SDM, whereas women and subjects with breast cancer were the least satisfied.

Half of all patients exhibit psychological distress and, of them, it reaches levels between moderate and severe in onethird; as such, they would require clinical care. This datum is in line with other studies that prove that the symptoms of psychological distress should be assessed throughout the entire course of their cancer [23]. Likewise, females exhibited greater distress than males (63 vs 44\%); patients under the age of 44 more than those $\geq 65$ years of age (66 vs $42 \%$ ), and those with stomach cancer more than the participants with colon cancer (68 vs $43 \%$ ). Of the sociodemographic variables, age and gender have been widely analyzed. Studies report that young people tend to develop psychological distress more often [24, 25], whereas women exhibit a greater sense of threat and emotional impact in the form of distress or post-traumatic stress than men [26, 27].

Apropos coping, approximately one in every four patients reported maladaptive coping strategies; specifically, hopelessness and anxious preoccupation, confirming the need to integrate psychosocial help into clinical practice as a way of improving quality of care for individuals with cancer [28]. As indicated in other studies, younger patients were the ones who confront cancer worse, presenting more hopelessness and psychological distress [29, 30]. Females, and in particular, those with breast cancer, were also the ones who displayed more psychological distress and anxious preoccupation [31, 32], and patients with stage III stomach cancer presented the most hopelessness.

This study is not without its limitations that must be taken into consideration. First of all, the use of self-report, subjective measures cannot accurately reflect patients' experiences, expectations, and behaviors, as they are limited by response bias (social desirability, inaccurate memory, etc.). Second, we have not factored in physician-based variables, such as age, gender, personality (e.g., empathic attitude, locus of control), or burnout, that have an important influence on the physician-patient relationship and on patient satisfaction [8]. Likewise, we have not taken into account variables, such as the characteristics of patients' personality, social and family support, or prior stressful events when accounting for patient satisfaction [33] and that should be taken into consideration in future research.

\section{Clinical repercussions}

Our study suggests that, bearing in mind the high prevalence of emotional distress and maladaptive strategies among oncological patients, doctors should contemplate 
Fig. 1 Perception of physician-patient interaction (SDM), emotional distress (BSI), and coping (Mini-MAC) by patient demographic (gender and age) and clinical (tumor and stage) characteristics. The data are presented in percentages

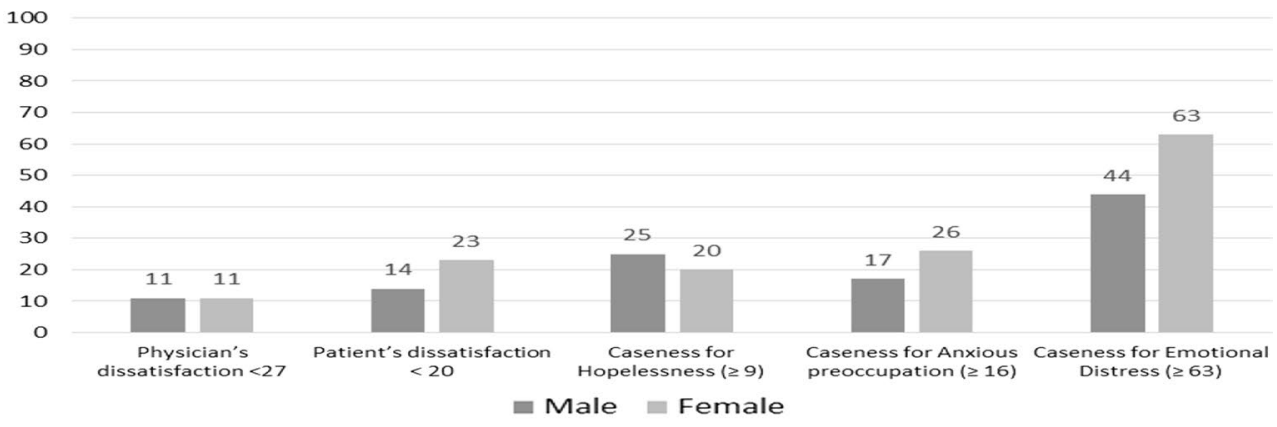

100

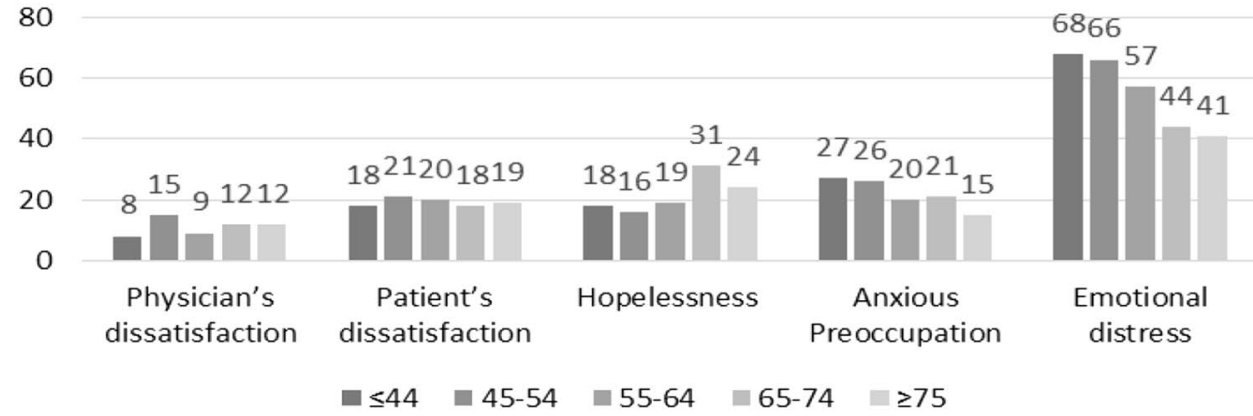

100

80

60

40

20

0

25

${ }_{7} 131615$

$16^{25} 13^{19}$

${ }^{23} 15$

28

Physician's dissatisfaction

Patient's

Hopelessness

dissatisfaction

n Colon Breast

Stomach

Others

Anxious

Preoccupation

Emotional distress $64^{68} 64$

3
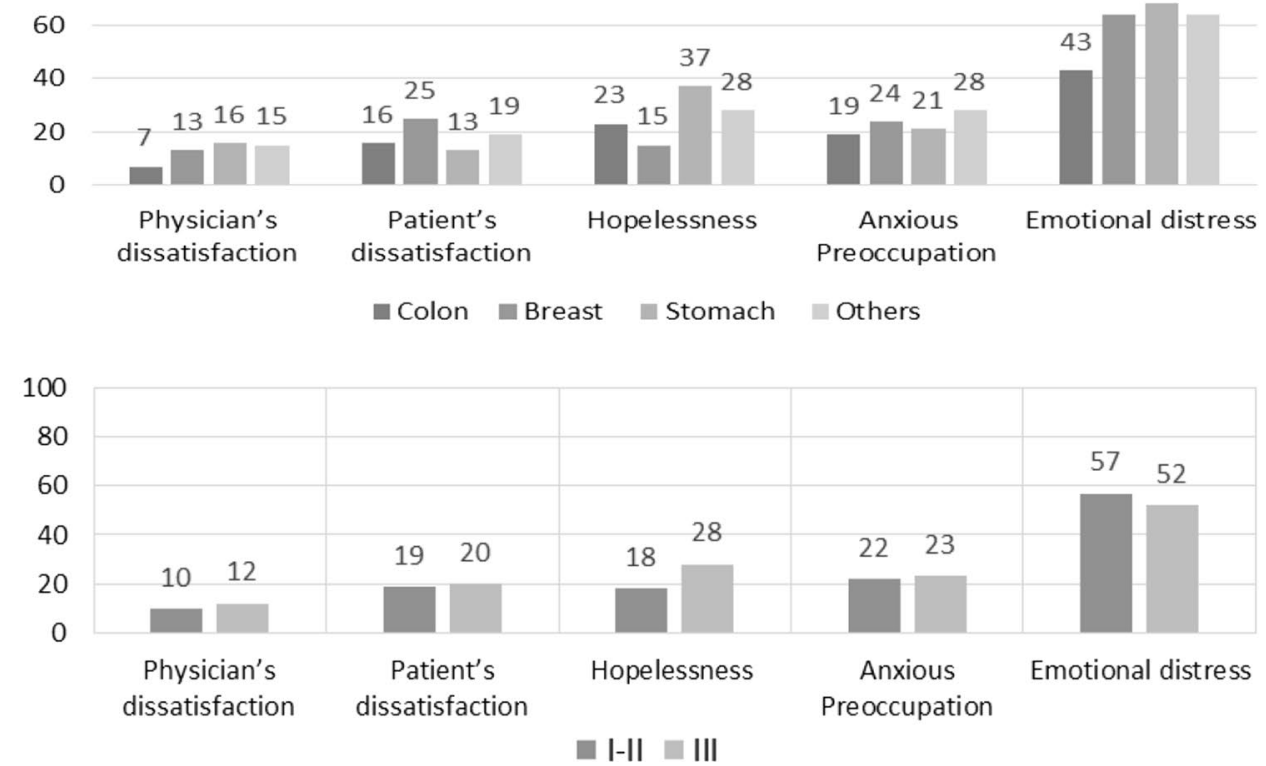

these variables when treating their patients and adapt their communication style accordingly. Young people and females generally perceive cancer as more aggressive and disruptive, not only because of its worse prognosis, but also because the diagnosis at a young age breaks with the natural and social history that tends to associate disease and demise with being elderly. We must also be mindful of the cultural aspects that need to be taken into account when analyzing psychosocial variables and in communication skills training when applied in a clinical context [33]. If we are to provide better quality of care, we must consider the patient's context and characteristics, as well as those of the cancer during screening, evaluation, and treatment.

Funding The study was supported by the FSEOM-Onvida for Projects on Long Survivors and Quality of Life. SEOM (Spanish Society of Medical Oncology) 2015. 


\section{Compliance with ethical standards}

Conflict of interest All authors declare that they have no conflict of interest. This is an academic study.

Ethical approval The study has been performed in accordance with the ethical standards of the Declaration of Helsinki and its later amendments. This study is an observational trial without intervention.

Informed consent Signed informed consent was obtained from all patients.

\section{References}

1. Mitchell AJ, Chan M, Bhatti H, Halton M, Grassi L, Johansen $\mathrm{C}$, et al. Prevalence of depression, anxiety, and adjustment disorder in oncological, haematological, and palliative-care settings: a meta-analysis of 94 interview-based studies. Lancet Oncol. 2011;12:160-74.

2. Travado L, Reis JC, Watson M, Borràs J. Psychosocial oncology care resources in Europe: a study under the European Partnership for Action Against Cancer (EPAAC). Psychooncology. 2017;530:523-30.

3. Grassi L, Berardi MA, Ruffilli F, Meggiolaro E, Andritsch E, Sirgo A, et al. Role of psychosocial variables on chemotherapyinduced nausea and vomiting and health-related quality of life among cancer patients: a European study. Psychother Psychosom. 2015;84:339-47.

4. Grassi L, Travado L, Moncayo FLG, Sabato S, Rossi E. Psychosocial morbidity and its correlates in cancer patients of the Mediterranean area: findings from the Southern European PsychoOncology Study. J Affect Disord. 2004;83:243-8.

5. Faller H, Weis J, Koch U, Brähler E, Härter M, Keller M, et al. Perceived need for psychosocial support depending on emotional distress and mental comorbidity in men and women with cancer. J Psychosom Res. 2016;81:24-30.

6. Ross L, Petersen MA, Johnsen AT, Lundstrøm LH, Groenvold M. Cancer patients' evaluation of communication: a report from the population-based study 'The Cancer Patient's World'. Support Care Cancer. 2013;21:235-44.

7. Mathews M, Ryan D, Bulman D. What does satisfaction with wait times mean to cancer patients? BMC Cancer. 2015;15:1017.

8. De Vries AMM, Roten Y, Meystre C, Passchier J, Despland J, Stiefel F. Clinician characteristics, communication, and patient outcome in oncology: a systematic review. Psycho-Oncology. 2014;23:375-81.

9. Gilbar O, Zusman A. The correlation between coping strategies, doctor-patient/spouse relationships and psychological distress among women cancer patients and their spouses. Psycho-Oncology. 2007;16:1010-8.

10. Blanch-Hartigan D, Chawla N, Beckjord EI, Forsythe LP, de Moor JS, Hesse BW, et al. Cancer survivors' receipt of treatment summaries and implications for patient-centered communication and quality of care. Patient Educ. 2015;98:1274-9.

11. Scholl I, Kriston L, Dirmaier J, Buchholz A, Härter M. Development and psychometric properties of the Shared Decision Making Questionnaire-physician version (SDM-Q-Doc). Patient Educ Couns. 2012;88:284-90.

12. Calderon C, Ferrando PJ, Carmona-Bayonas A, Lorenzo-Seva U, Jara C, Beato C, et al. Validation of SDM-Q-Doc Questionnaire to measure shared decision-making physician's perspective in oncology practice. Clin Transl Oncol. 2017;19:1-8.
13. Kriston L, Scholl I, Hölzel L, Simon D, Loh A, Härter M. The 9-item Shared Decision Making Questionnaire (SDM-Q-9). Development and psychometric properties in a primary care sample. Patient Educ Couns. 2010;80:94-9.

14. De las Cuevas C, Perestelo-Perez L, Rivero-Santana A, CebollaMartí A, Scholl I, Härter M. Validation of the Spanish version of the 9-item Shared Decision-Making Questionnaire. Health Expect. 2015;18:2143-53.

15. Simon D, Schorr G, Wirtz M, Vodermaier A, Caspari C, Neuner B, et al. Development and first validation of the shared decision-making questionnaire (SDM-Q). Patient Educ Couns. 2006;63:319-27.

16. Watson M, Law MG, dos Santos M, Greer S, Baruch J, Bliss J. The Mini-MAC. J Psychosoc Oncol. 1994;12:33-46.

17. Anagnostopoulos F, Kolokotroni P, Spanea E, Chryssochoou M. The Mini-Mental Adjustment to Cancer (Mini-MAC) scale: construct validation with a Greek sample of breast cancer patients. Psycho-Oncology. 2006;15:79-89.

18. Vodermaier A, Linden W, Siu C. Screening for emotional distress in cancer patients: a systematic review of assessment instruments. J Natl Cancer Inst. 2009;101:1464-88.

19. Derogatis LR. BSI 18, Brief Symptom Inventory 18: administration, scoring and procedures manual. Minneapolis: NCS Pearson, Inc.; 2001.

20. Andreu Y, Galdón MJ, Dura E, Ferrando M, Murgui S, García A, et al. Psychometric properties of the Brief Symptoms Inventory-18 (BSI-18) in a Spanish sample of outpatients with psychiatric disorders. Psicothema. 2008;20:844-50.

21. Martín-Fernández R, Abt-Sacks A, Perestelo-Perez L, SerranoAguilar P. Shared decision making in breast cancer womens' attitudes. Rev Esp Salud Publica. 2013;87:59-72.

22. Padilla-Garrido N, Correa FA, Moreno MO, Calero JB, Lozano EB. La toma de decisiones compartidas desde la perspectiva del paciente oncológico: roles de participación y valoración del proceso. An Sist Sanit Navar. 2017;40:25-33.

23. Meggiolaro E, Berardi MA, Andritsch E, et al. Cancer patients' emotional distress, coping styles and perception of doctor-patient interaction in European cancer settings. Palliat Support Care. 2016;14:204-11.

24. Jansen L, Hoffmeister M, Chang-Claude J, Brenner H, Arndt V. Benefit finding and post-traumatic growth in long-term colorectal cancer survivors: prevalence, determinants and associations with quality of life. Br J Cancer. 2011;105:1158-65.

25. Nenova M, DuHamel K, Zemon V, Rini C, Redd WH. Posttraumatic growth, social support, and social constraint in hematopoietic stem cell transplant survivors. Psychooncology. 2013;22:195-202.

26. Yi J, Kim MA. Postcancer experiences of childhood cancer survivors: how is posttraumatic stress related to posttraumatic growth? J Trauma Stress. 2014;27:461-7.

27. McDonough MH, Sabiston CM, Wrosch C. Predicting changes in posttraumatic growth and subjective well-being among breast cancer survivors: the role of social support and stress. Psychooncology. 2014;23:114-20. https://doi.org/10.1002/pon.3380.

28. Jacobsen PB, Holland JC, Steensma DP. Caring for the whole patient: the science of psychosocial care. J Clin Oncol. 2012;30:1151-3.

29. Lang M, Giese-Davis J, Patten S, Campbell DJT. Does age matter? Comparing post-treatment psychosocial outcomes in young adult and older adult cancer survivors with their cancer-free peers. Psycho-Oncology. 2017 https://doi.org/10.1002/pon.4490.

30. Quinn GP, Gonçalves V, Sehovic I, Bowman ML, Reed DR. Quality of life in adolescent and young adult cancer patients: a systematic review of the literature. Patient Relat Outcome Meas. 2015;6:19-51. 
31. Ng CG, Mohamed S, Kaur K, Sulaiman AH, Zainal NZ, Taib NA, et al. Perceived distress and its association with depression and anxiety in breast cancer patients. PLoS One. 2017;12:e0172975.

32. Linden W, Vodermaier A, MacKenzie R, Greig D. Anxiety and depression after cancer diagnosis: prevalence rates by cancer type, gender, and age. J Affect Disord. 2012;141:343-51.
33. Thorne S, Hislop TG, Kim-Sing C, Oglov V, Oliffe JL, Stajduhar KI. Changing communication needs and preferences across the cancer care trajectory: insights from the patient perspective. Support Care Cancer. 2014;22:1009-15. 